\title{
IoT Project Management
}

\author{
Vlad HURTOI, Daniel AVADANEI \\ Bucharest University of Economic Studies \\ hurtoiv@gmail,avadaneida@gmail.com
}

In this paper the authors are analyzing the difficulties in managing an IoT project and present a general overview of managers on IoT projects. Based on a survey [10] one of the main causes of failing project are technical or managerial skills and lack of communication. Due to the increase difficulty of these kind of projects managers are choosing hybrid management techniques [10] in order accommodate to IoT projects. Project managers should be involved from the early stages of the project even in the technical issues that may appear, issues addressed in other types of projects by technical people. Even from the research phase of the project. In IoT projects the project management should have a backup plane due to the high risk of failure.

Keywords: Internet of Things, Cloud Computing, Wireless communication, RFID, Agile

DOI: $10.24818 /$ issn14531305/24.3.2020.07

\section{I} nternet of Things

The Internet of Things is a new paradigm in software and hardware industry which envision a global network of devices interconnected using Internet technology or a certain protocol like UDP or TCP. The power of IOT technology resides in the capability of connecting with devices that are also integrated in business processes like vending machines, business intelligence applications or customers supply systems facilitating the business processes. For example, UPS is using IoT enabled fleet tracking technologies to cut costs while Amazon is set to use drones which uses IoT technology in order to deliver products and packages. The statistics forecasts that by 2020 IoT market will reach 26 billion units, up from one billion in 2009.

There are five IoT technologies that are successfully implemented in IoT software and hardware:

- Radio frequency identification (RFID): allows identifications and capture of data using radio waves, a tag and a reader. The tag contains data in the format of EPC, a global RFID identification system.

- Wireless sensor networks (WSN): consist of devices which are using wireless network in order to communicate, devices which also can cooperate with RFID systems. WSN has been used mainly in temperature sensitive products. For example, General Electrics deploys sensors in jet engines, turbines and wind farms which are capable of collecting and storing more than 20 terabytes of data.

- Middleware: IoT devices also supports different interfaces in order to access the functionality of the devices without being necessary to know all the components requirements. For example, Global Sensors Network is an open-sensor middleware using IoT integrated technology which is enabling developers to program and deploy sensors services with little with no programming effort.

- Cloud Computing: IoT services are capable of generating huge amounts of data that can be difficult to store especially in devices that are small and cannot hold a huge database. Here, the integration of IoT with cloud computing systems is helping in devices like servers, networks, applications and can be provisioned as Infrastructure as a Service (IaaS) or Software as a Service.

- IoT applications: IoT device enable human to devices interactions in a properly time and manner. For example the transportation of objects that are sensitive to heat and need to be stored in a 
cold environment or in an environment which needs attention to temperature, humidity or shock are using sensors to monitor all these values and appropriate actions are taken automatically in order to avoid spoilage when connection is out of range. FedEx uses Sense Aware to keep objects on the temperature, location and other vital signs of a package.

\section{Agile methodology in project management}

There are two completely different methods in developing an IT solution, the Agile and the Waterfall models. There are some key difference between those two models:

- In Agile the process is broken into smaller models, where the Waterfall is not.

- The customer can only see the final product at the end of the project in the waterfall model, where in Agile the customer gives his feedback at the end of each sprint.

- Errors and bug can be fixed anytime, based on the severity in the Agile model, where in the Waterfall model they can only be fixed at the end of the project as testing part is done only at the end.

- Software development is a top priority in Agile over the documentation, where in Waterfall documentation is top priority.

- As the process is broken in smaller processes in Agile finished features can be delivered to the client where in Waterfall only the final product is delivered to the client.

- In Waterfall the testers are not in direct contact with the developers and each department works separately where in Agile everyone is involved in the developing process.

In IT project the success rate is grater in Agile model then in Waterfall. More importantly the failed percentage is lower in Agile and as the IT project can be very costly the risk of failing can have a huge impact on the company that tries to create such project. In Agile the project management can break the project in several stages where they can have constant input and collaborate with parties involved in the project. The product can have multiple iteration and constantly be improved from the feedback of the client and all parties involved. At the beginning of the project the client describes at a very high level how the end product should look. The product team then come up with a solution and present it to the client. After more discussion, the bases of the product are defined and agreed on. In each iteration of the product the client can give his approval and make changes.

\section{Project management in IoT projects}

Studying the management data there are some issues regarding project management in IoT field. According to a 2017 Cisco Survey about $75 \%$ of IOT projects are, this issue having a negative impact on several industries which are feeling less confident in investing money in IoT business as is seen as a risky business [1]. Historically, project managements are built around system development life cycle, where waterfall or agile methodologies play an important role in defining, designing, developing, testing and then deploying the final product. In IoT projects, one can expect longer project timelines, lack of silos, comprehensive testing, strict rules around compliance, planning and security, demanding a revise in management planning. The issue that appears is the scalability of management processes, tools and techniques to successfully complete IoT projects.

The Cisco survey underlined one main cause of IoT projects failing being the "human factor", including weak technical or managerial skills, lack of communication or the overall culture. Also, lack of accepted and recognized technical and managerial "jargon" is causing problems in interoperability when comes to management of IoT projects [2]. Usually, IoT projects have longer project timelines, testing time being higher than in other ordinary technical projects [3]. The field of IoT will affect the project management, new project management styles being required as the risk involved in different phases of product development, the compliance and security risk is different compared to other software and hardware projects [3]. 
Projects will need to be managed differently than traditional IT projects, hardware or software. Five phases, namely: collect, transport, store, analyze and archive of an IoT project should be streamlined with the current Project Management Institute (PMI) project phases, i.e. with Initiation, Planning, Execution, Monitoring and Control, and Closing [4].

Also, the project manager should be involved in the research and development phase of an IoT project [5]. For example, in the Amazon drone delivery project, an IoT project, managers would be involved from research and development phase, going through the whole process of managing and developing the way drones communicate with air traffic controllers, corporate office, and delivery of product to the end customer. The necessity of involving the managers of IoT projects into the technical issues would be the fact that the number of jobs for managers will reduce in the future while the jobs for the skilled people will increase [6].The IoT will disrupt the project management in different ways, as the data from sensors will help companies reduce downtime, save money, increase the productivity and help determining the amount of new workforce needed.

The project managers would need to expect lengthier and onsite jobs [7]. In order to lead a successful IoT project a manager will need to always have a plan B or an exit strategy, plan better risk management; including the vendor risk, making it easy to replace or update the IoT components and finally to have buy-in from across the organization [8].

Over the time many approaches to project management have been tried: Kanban, Agile, Disciplined Agile Delivery, Scrum, Extreme Programming and different Agile methodologies in order to accommodate the Big Data, SOA(Service Oriented Architecture) based products and IoT products [9]. The impact of these approaches over the IoT projects has been poorly studied due to lack of data over time so it remains uncertain which of these strategies are better for IoT projects. According to a study made by Vikram Prasher [10] in 2018, the managers in the 34 IoT firms that were implicated in the web-based study preferred agile methodology and a hybrid of waterfall and agile features in IoT based projects:

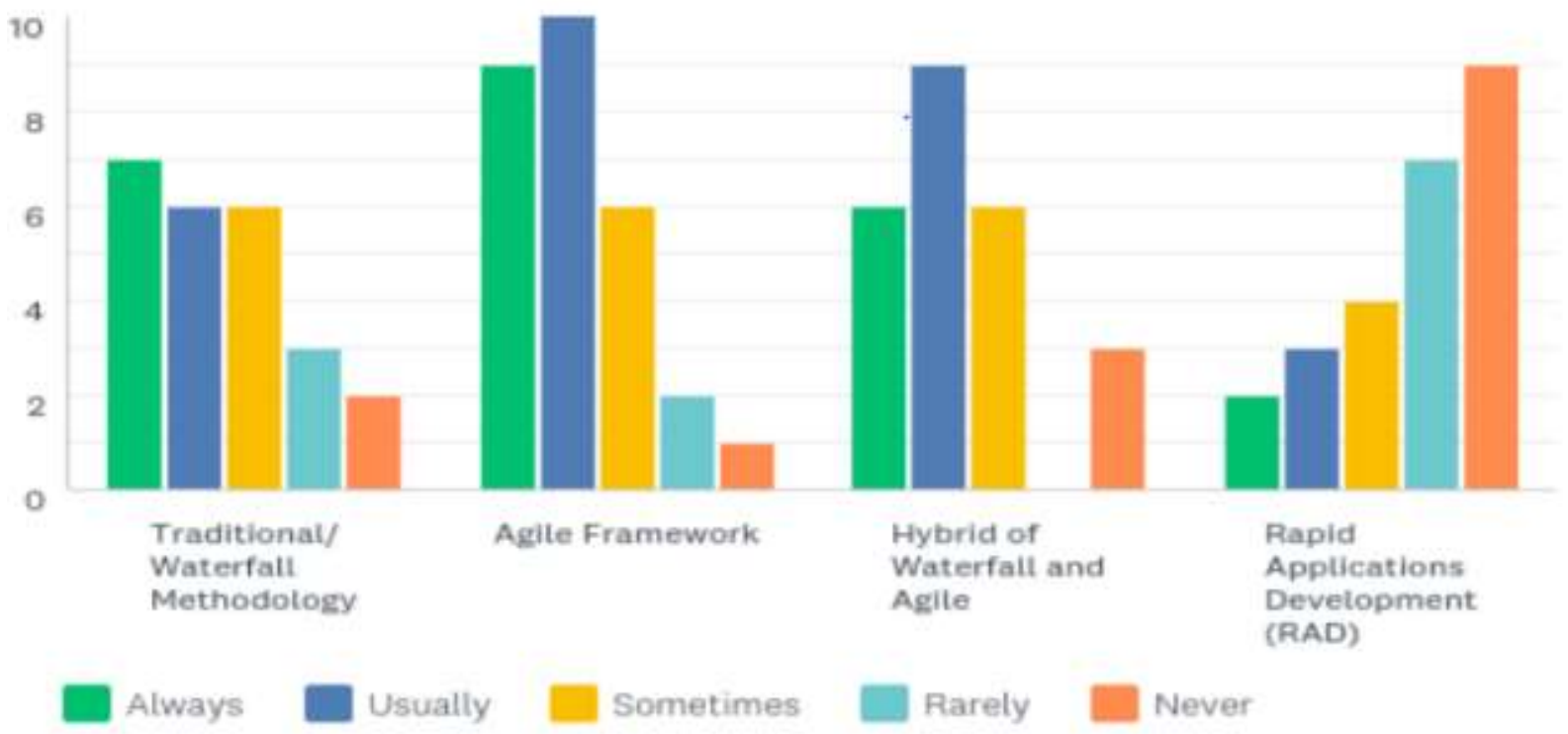

Fig.1 Managers choosing methodologies for IoT projects [10]

In order to better understand the impressing impact of the IoT in business and the managers decisions in IoT projects, this study presents an overview of data collected from managers which are directly implicated in IoT studies. In the table 1 are presented data from studies, interviews, press and scientific articles. 
Table 1. Executives in IoT projects

\begin{tabular}{|l|l|}
\hline Content & \multicolumn{1}{|c|}{ Details } \\
\hline $\begin{array}{l}\text { About 58\% of financial executives report } \\
\text { having high-developed IoT initiatives } \\
\text { (Forbes)[16] }\end{array}$ & $\begin{array}{l}\text { A Forb Insights survey of about } 700 \\
\text { executives from financial services shows that } \\
\text {,close to six in 10 executives,58\%,report } \\
\text { having well developed IoT initiatives } .\end{array}$ \\
\hline $\begin{array}{l}\text { Digital transformation is a top strategic } \\
\text { objective 94\% of executives (Delloite)[15] }\end{array}$ & $\begin{array}{l}\text { A Deloitte Industry 4.0 survey of 361 } \\
\text { executives across 11 countries shows that } \\
94 \% \text { report digital transformation as their } \\
\text { organization's top strategic initiative. }\end{array}$ \\
\hline $\begin{array}{l}\text { 80\% of organizations report positive } \\
\text { results (Moore)[18] }\end{array}$ & $\begin{array}{l}\text { A Gartner study indicates that 80\% of } \\
\text { surveyed organizations that have adopted } \\
\text { IoT are achieving "better-than-expected } \\
\text { results." }\end{array}$ \\
\hline $\begin{array}{l}\text { 85\% of respondents say they have IoT } \\
\text { project budgets (MacGillivray) }\end{array}$ & $\begin{array}{l}\text { A recent International Data Corporation } \\
\text { (IDC) report indicates that of the 5,421 } \\
\text { survey respondents from 29 countries, the } \\
\text { overwhelming majority have dedicated } \\
\text { budgets to IoT projects. }\end{array}$ \\
\hline $\begin{array}{l}\text { 152,200 IoT devices per minute } \\
\text { (Rosen)[19] }\end{array}$ & $\begin{array}{l}\text { IDC data estimates that 152,200 IoT devices } \\
\text { will be connected every minute by 2025, } \\
\text { meaning that by 2025, nearly 80 billion } \\
\text { (79,996,320,000) devices are forecast to be } \\
\text { connected annually. }\end{array}$ \\
\hline
\end{tabular}

\section{Conclusion}

This study presented an overview of the issues that the managers may be facing in the field of IoT, the preferred styles of managements that the managers would use in IoT field and an abstract of statistical data that shows the general feeling of managers about the IoT field. The general conclusion from this study is that not the style of managing a project is impacting in general the IoT projects, but the field of IoT itself is impacting the different management styles and the managers themselves as they are adapting to new technologies using hybrid agile methodologies and getting themselves involved more in the technical part of the projects. The future of management in IoT will be dictated by the technology itself and not by the new paradigms in management.

\section{References}

[1] Cisco, Cisco Survey Reveals Close to Three-Fourths of IoT Projects Are Failing, available https://newsroom.cisco.com/pressrelease-content?articleId=1847422, 2017.

[2] R.M. Dijkman, B. Sprenkels, T. Peeters, A. Janssen, Business models for the Internet of Things, International Journal of Information Management, 35, 2015, pp. 672-678.

[3] A. Scroxton, Enterprise IoT projects will be costly, lengthy and vulnerable, says Gartner, available at: https://www.computerweekly.com/news/ 4500270831/Enterprise-IoT-projectswill-be-costly-lengthy-and-vulnerablesays-Gartner, 2016.

[4] M. Bekker, The five phases of an IoT project, available at: http://www.techsmart.co.za/business/The -five-phases-of-an-IoTproject.html, 2017.

[5] W. Curlee, Episode 337: Internet of Things (IoT) Projects may Fundamentally Change Project Management. (C. Fichtner, Interviewer), available at: https://www.mixcloud.com/theprojectma nagementpodcast/episode-337-internetof-things-iot-projects-may- 
fundamentally-change-projectmanagement-free-p/, 2015.

[6] Prescient, How Internet of Things (IoT) relates with Project Management, available at: http://www.psgincs.com/how-internet-ofthingsiotrelates-with-projectmanagement/, 2016.

[7] D. Newman, Disrupting Project Management with the IoT, available at: https://fowmedia.com/disrupting-projectmanagement-with-the-iot/, 2018.

[8] B. Buntz, How Not to Manage an IoT Project: 7 Common Pitfalls, available at: http://www.ioti.com/strategy/how-notmanage-iot-project-7-commonpitfalls, 2016.

[9] I. Jacobson, I. Spence, P.-W. Ng, Is There a Single Method for the Internet of Things?, Communications of the ACM, November 2017, Vol. 60 No. 11, pp. 4653

[10] V. S. Prasher, Internet of Things (IoT) and Changing Face of Project Management, Dissertations Theses, 2018

[11] Agile Methodology \& Model: Guide for Software Development \& Testing, available at: https://www.guru99.com/agile-scrumextreme-testing.html, 2020

[12] Wrike, FAQ, available at: https://www.wrike.com/projectmanagement-guide/faq/what-is-agile- methodology-in-project-management/, 2020

[13] I. Lee, K. Lee, The Internet of Things (IoT): Applications, investments, and challenges for enterprises, Business Horizons, vol. 58, Issue 4, July-August 2015, pp. 431-440.

[14] V. Aleksandrovičs, E. Filičevs, J. Kampars3, Internet of Things: Structure, Features and Management, Information Technology and Management Science, vol. 18, 2016, pp. 78-84.

[15] A. Daecher et al, Delloite Insights, The Industry 4.0 paradox, 2018.

[16] Forbes Insights, How IoT Is Impacting 7 Key Industries Today, Forbes, available at: https://www.forbes.com/sites/insightsinteliot/2018/08/24/how-iot-is-impacting7-key-industries-today/, 2018

[17] C. MacGillivray, S. Crook, Global IoT Decision-Maker Survey, 2019: First Look, 2019

[18] S. Moore, Lessons from IoT Early Adopters, available at: https://www.gartner.com/smarterwithgart ner/lessons-from-iot-early-adopters/, 2018.

[19] M. Rosen, Driving the Digital Agenda, available at: https://idccema.com/dwn/SF_177701/driving_the_ digital_agenda_requires_strategic_archite cture_rosen_idc.pdf, 2015. 


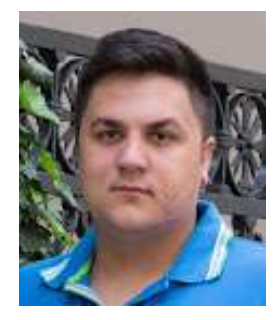

Vlad HURTOI has graduated The Faculty of Business Administration (in Foreign Languages) from Bucharest University of Economic Studies in 2018. Now he is a student in the master's program of Economic Informatics at the same university. $\mathrm{He}$ is a full-time developer working on the FintechOS platform.

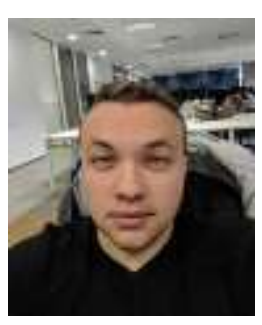

Daniel AVADANEI is a graduated of Faculty of Economic Cybernetics, Statistics and Informatics at Bucharest University of Economic Studies, passionate about economy and technology with experience in software and banking, always looking for the next big thing in the IT field. 